\title{
The diagnostic value of matrix metalloproteinase 9 (MMP-9) and tissue inhibitor of matrix metalloproteinases 1 (TIMP-1) determination in the sera of colorectal adenoma and cancer patients
}

\author{
Barbara Mroczko • Magdalena Groblewska • \\ Bogna Okulczyk • Bogusław Kędra • \\ Maciej Szmitkowski
}

Accepted: 4 June 2010 / Published online: 17 June 2010

(C) The Author(s) 2010. This article is published with open access at Springerlink.com

\begin{abstract}
Purpose Tumor cells, including colorectal cancer (CRC), are able to produce and release matrix metalloproteinase 9 (MMP-9) which is involved in tumor invasion and metastasis. Natural tissue inhibitors of matrix metalloproteinases (TIMPs) regulate activity of MMPs and stimulate tumor growth and malignant transformation. The aim of the present study was to compare the clinical significance of serum MMP-9 with TIMP-1 in the diagnosis of CRC patients and in the differentiation between colorectal adenoma (CA) and cancer.

Methods Serum MMP-9 and TIMP-1 were measured in 75 CRC patients, $35 \mathrm{CA}$, and 70 healthy subjects using enzyme-linked immunosorbent assay. Concentrations of carcinoembryonic antigen (CEA) and carbohydrate antigen 19-9 (CA 19-9) were determined by microparticle enzyme immunoassay.

Results Serum levels of all proteins tested were significantly higher in CRC patients than in healthy subjects. Additionally, serum TIMP-1 was significantly higher in patients with CRC than in CA patients. Concentrations of TIMP-1 correlated with tumor stage, nodal involvement, presence of distant metastases, patients' survival, and tumor resectability. Diagnostic sensitivity of TIMP-1 was higher (61\%) than those of
\end{abstract}

B. Mroczko $(\bowtie) \cdot$ M. Groblewska $\cdot$ M. Szmitkowski

Department of Biochemical Diagnostics, Medical University,

Waszyngtona 15 a,

15-269 Białystok, Poland

e-mail: mroczko@umwb.edu.pl

B. Okulczyk · B. Kędra

Second Department of General Surgery, Medical University,

Białystok, Poland other biomarkers (MMP-9, 55\%; CEA, 39\%; CA 19-9, $11 \%)$, and increased in combined use with MMP-9 $(75 \%)$ or CEA (73\%). The areas under receiver operating characteristic curves of TIMP-1 were larger than those of MMP-9.

Conclusions Our findings suggest better usefulness of serum TIMP-1 than MMP-9 in the diagnosis of CRC, especially in the assessment of Duke's classification of tumor stage, survival of cancer patients, resectability of tumor, and in the differentiation between CA and cancer.

Keywords Colorectal cancer . Colorectal adenoma .

MMP-9 · TIMP-1 · Tumor markers

\section{Introduction}

Colorectal cancer (CRC) is one of the most frequent malignant tumors in the industrialized world - it is estimated as the third leading cause of new cancer cases, as well as malignancyrelated death [1]. The largest risk of CRC development is observed in patients with genetic predispositions or with sporadic adenomatous polyps [2]. Colorectal carcinogenesis is a complex, long-term, and multi-step process of malignant transformation from normal epithelium to cancer cells, which involves numerous genetic changes and results in various phenotypic alterations [3]. The adenomatous polyps are neoplastic tumors with a potential to develop into invasive adenocarcinoma of the colon or rectum. Sequence of events includes adenomatous polyps of the colon or rectum, through grades of increasing dysplasia to carcinoma in situ.

Although proteolytic degradation of extracellular matrix (ECM) is observed in many physiological conditions, it plays a role in development of malignant tumors as a key 
step in the regulation of cancer proliferation [4]. It was shown that tumor cells, including CRC, are able to produce and release matrix metalloproteinase 9 (MMP-9), a proteolytic enzyme capable of degrading the basement membrane and type IV collagen in the ECM. Degradation of collagen by MMP-9 is involved both in tumor invasion and metastasis [5]. Increased expression of this enzyme in CRC cells was associated with enhanced invasiveness of tumor [6]. Elevated serum or plasma levels of MMP-9 were observed in patients with colorectal [7], gastric [8], lung [9], and breast cancer [10].

Naturally occurring tissue inhibitors of matrix metalloproteinases (TIMPs) partly regulate the proteolytic activity of MMPs. TIMP-1 binds and inhibits MMP-9 in a 1:1 stoichiometric proportion. Increased expression of TIMP-1 correlates with overexpression of MMP-9, although regulation of one of these proteins by another may be an independent process, resulting in a local imbalance of MMP activity [11]. This lack of balance between MMPs and TIMPs is an important factor in the development of gastrointestinal malignancies [4]. It was demonstrated that TIMPs might stimulate tumor growth and malignant transformation [12], as well as inhibit tumor cell apoptosis [13]. Therefore, it was suggested that TIMP-1 might play a dual role in the regulation of cancer progression and metastasis.

Enhanced expression of TIMP-1 in tumor tissues was observed in CRC [12] and breast cancer [14]. Elevated concentrations of this protein were detected in patients with metastatic prostate cancer and CRC [15-17]. Increased plasma level of TIMP-1 was a significant prognostic factor for the survival of patients with colorectal [18-21], lung [9] and breast cancer [10].

It has been proposed that MMPs and TIMPs might play a role not only in colorectal tumor invasion and initiation of metastatic cascade, but also in colorectal carcinogenesis from adenomatous polyps. The expression of MMP-9 in CRC tissue was significantly higher in comparison with colorectal adenoma (CA), or the normal mucosa and staining intensity correlated with the grade of CRC [22]. Moreover, significantly higher expression of MMP-9 has been observed in adenomas with high grade dysplasia compared to other adenomas or normal colon tissue [22].

Tissue samples from various steps of colorectal carcinogenesis, e.g., tubular adenomas, tubovillous adenomas, villous adenomas, and colorectal adenocarcinomas were examined by immunocytochemical staining for the presence of MMP-9 and TIMP-1. The immunolocalization of MMP-9 and TIMP-1 increased gradually from tubular adenomas to villous adenomas, and in carcinomas in situ, a definite positive expression of these proteins was shown. This increasing expression of MMP-9 and TIMP-1 coincides with a multi-step process of colonic tumorigenesis [23]. Moreover, the activity of MMP-9 determined in zymography was significantly higher in CRC tissue than in adenomas or normal mucosa [24].

The aim of the present study was to compare the clinical significance of serum MMP-9 with TIMP-1 measurement in the diagnosis of CRC patients, as well as in the differentiation between $\mathrm{CA}$ and cancer. We determined the concentrations of MMP-9 and TIMP-1 in the sera of CRC patients in relation to clinico-pathological features of cancer and serum levels of classical tumor markers: carcinoembryonic antigen (CEA) and carbohydrate antigen 19-9 (CA 19-9). Moreover, we assessed the diagnostic sensitivity and areas under receiver operating characteristic (ROC) curves for all the proteins tested.

\section{Material and methods}

\section{Patients}

The study included a total number of 180 subjects: 75 previously untreated CRC patients, $35 \mathrm{CA}$ patients, and 70 healthy subjects. The subjects were CRC patients (28 women and 47 men, aged $27-83$ years) and CA patients (13 women and 22 men, aged 32-78 years) diagnosed from September 2003 to May 2006 and operated at the Second General Surgery Department of the Białystok Medical University Hospital; the control group comprised of 20 women and 15 men, aged 20-69 years. Physical examination, blood tests, chest x-rays, abdominal ultrasound, and computed tomography were used in the clinical diagnosis of the patients. The diagnosis of CRC or CA was confirmed by microscopic examination of the tumor samples obtained during colonoscopy, biopsy, and/or surgery. The subjects who had suffered a heart attack or heart failure were not included in the study. Moreover, the patients with extraintestinal tumors and those after preoperative radiochemotherapy were excluded from the study.

Sixty-seven CRC patients underwent surgical tumor resection, while eight patients had non-resectable tumors. The staging of cancer was based on a routine postoperative histopathological analysis and clinical assessment according to Duke's classification [25]. For statistical analysis, the CRC patients were divided into three groups: 28 cancer patients in stage B, 27 patients in stage $\mathrm{C}$, and 20 patients in stage $\mathrm{D}$, and then sub-divided into: three groups depending on the infiltration of the bowel wall (T2, T3, and T4), four groups depending on nodal involvement (N0, $\mathrm{N} 1$, N2, and N3), two groups depending on the presence of distant metastases (M0 and M1). Twelve CRC patients died of cancer during the 2-year observation period, whereas 63 patients survived. The number of patients in the analyzed subgroups is shown in Table 1. The study was approved by the local ethics committee, the study number is R-I-002/ 
Table 1 Characteristics of colorectal cancer patients

\begin{tabular}{|c|c|c|}
\hline \multicolumn{2}{|l|}{ Variable analyzed } & \multirow{2}{*}{$\begin{array}{c}\begin{array}{l}\text { Number } \\
\text { of patients }\end{array} \\
75\end{array}$} \\
\hline Group & Colorectal cancer & \\
\hline & Colorectal adenoma & 35 \\
\hline & Control group & 70 \\
\hline \multirow[t]{5}{*}{ Duke's stage } & B1 & 3 \\
\hline & B2 & 25 \\
\hline & $\mathrm{C} 1$ & 19 \\
\hline & $\mathrm{C} 2$ & 8 \\
\hline & $\mathrm{D}$ & 20 \\
\hline \multirow[t]{3}{*}{ TNM classification } & stage II & 28 \\
\hline & stage III & 27 \\
\hline & stage IV & 20 \\
\hline \multirow[t]{2}{*}{ Tumor localization } & colon & 54 \\
\hline & rectum & 21 \\
\hline \multirow[t]{3}{*}{ Bowel wall infiltration ( $\mathrm{T}$ factor) } & $\mathrm{T} 2$ & 4 \\
\hline & $\mathrm{T} 3$ & 56 \\
\hline & $\mathrm{T} 4$ & 15 \\
\hline \multirow[t]{4}{*}{ Nodal involvement ( $\mathrm{N}$ factor) } & No & 29 \\
\hline & $\mathrm{N} 1$ & 21 \\
\hline & $\mathrm{N} 2$ & 16 \\
\hline & N3 & 9 \\
\hline \multirow[t]{2}{*}{ Distant metastases ( $\mathrm{M}$ factor) } & M0 & 55 \\
\hline & M1 & 20 \\
\hline \multirow[t]{2}{*}{ Resectability of tumor } & Resectable & 67 \\
\hline & Nonresectable & 8 \\
\hline \multirow[t]{2}{*}{ Patients' survival } & Alive & 63 \\
\hline & Dead & 12 \\
\hline
\end{tabular}

$285 / 2009$. All the patients gave their informed consent to participate in the study.

\section{Biochemical analyses}

Blood samples from all the patients were drawn before surgical treatment. None of the CRC patients had received chemo- or radiotherapy before blood sample collection. To standardize clotting conditions, all sera were separated within $1 \mathrm{~h}$ after blood collection, aliquoted and stored at $-80^{\circ} \mathrm{C}$ until assayed.

Serum levels of MMP-9 and TIMP-1 were measured using enzyme-linked immunosorbent assay kits (R\&D Systems, Abingdon, England) according to the manufacturer's instructions. The serum samples were diluted 100-fold before determination. The manufacturer of assay kits referred to the intra-assay coefficient of variation $(\mathrm{CV}$ $\%$ ) as $1.9 \%$ at MMP-9 mean concentration of $2.04 \mathrm{ng} / \mathrm{mL}$, $\mathrm{SD}=0.039$ and as $3.9 \%$ at TIMP-1 mean concentration of $1.27 \mathrm{ng} / \mathrm{mL}, \mathrm{SD}=0.05$. Serum concentrations of CEA and carbohydrate antigen 19-9 (CA 19-9) were measured by microparticle enzyme immunoassay kits (Abbott, Chicago, Illinois). The intra-assay $\mathrm{CV}$ for CEA is reported by the manufacturer of the assay kits to be $4.9 \%$ at a mean concentration of $2.2 \mathrm{ng} / \mathrm{mL}, \mathrm{SD}=0.11$ and the intra-assay $\mathrm{CV} \%$ for CA $19-9,4.7 \%$ at a mean concentration of $38.2 \mathrm{IU} / \mathrm{mL}, \mathrm{SD}=1.80$. The reference cut-off values for tumor markers (the 95th percentile) were established previously in our department by examining blood sera of healthy volunteers [26]. The cut-off points were $4.0 \mathrm{ng} / \mathrm{mL}$ for CEA and 30.0 IU/mL for CA 19-9. The cut-off points for serum levels of MMP-9 (480 ng/mL) and TIMP-1 (203 ng/mL) were determined using Microsoft Office Excel software. In the ROC report generated by this program, the cut-off value corresponds to the highest accuracy (minimal false-negative and false-positive results).

\section{Statistical analysis}

A preliminary statistical analysis ( $\chi 2$ test) revealed that serum levels of MMP-9, TIMP-1, CEA, and CA 19-9 did not follow a normal distribution. Therefore, nonparametric statistical analyses were used. The stages B1 and B2 were analyzed as one group (stage $\mathrm{B}$ ), whereas stages $\mathrm{C} 1$ and $\mathrm{C} 2$ - as stage $\mathrm{C}$ because of small numbers of patients in the particular subgroups. The Mann-Whitney $U$ test was used to compare the two groups in each category (the controls versus CRC or CA patients; M0 versus M1 group; the group of patients who survived versus patients who died of CRC; resectable tumors versus nonresectable). Differences between more than two groups (e.g., stage B, C, D; or T2, T3, T4; or N0, N1, N2, N3) were compared using ANOVA on ranks (Kruskal-Wallis tests). If significant differences were found, the post hoc Dwass-Steele-Critchlow-Fligner test was conducted to determine which groups were different. Differences were considered statically significant with $p$ values below 0.05 . Moreover, we calculated diagnostic criteria such as percentage of elevated levels (diagnostic sensitivity) and area under the ROC curve (AUC) for the MMP-9, TIMP-1, and tumor markers. Statistical analyses were carried out using the STATISTICA 5.1 PL program (StatSoft Inc., Tulsa, OK). Diagnostic criteria and the ROC curves were calculated using MedCalc statistical software (MedCalc Software, Mariakerke, Belgium) and Microsoft Office Excel program (Microsoft Corporation, Redmond, WA).

\section{Results}

Serum concentrations of MMP-9, TIMP-1, CEA, and CA 19-9 in colorectal cancer and colorectal adenoma patients

Concentrations (median and range) of MMP-9, TIMP-1, and tumor markers in the sera of CRC and adenoma 
patients, as well as in healthy subjects are presented in Table 2. Serum levels of all proteins tested were higher in $\mathrm{CRC}$ patients than in CA patients and healthy controls. The differences between CRC patients and control group were significant for all measurands, but between CRC and CA patients, only concentrations of TIMP-1 and CEA were significant. Moreover, levels of MMP-9 and TIMP-1 were significantly higher in adenoma group in comparison with healthy subjects. The differences between the analyzed groups were confirmed in Dwass-Steel-Critchlow-Fligner post hoc tests, and statistical significance was found for the comparison of MMP-9 levels in CA patients and healthy controls; for CEA, in comparison of CRC with adenoma patients and CRC with control group; but for TIMP-1 level, for all analyzed pairs.

The concentrations of MMP-9 and TIMP-1 in patients with colonic cancer were higher, but levels of tumor markers are lower than those in rectal cancer subgroup. The differences were significant only for serum MMP-9.

Levels of MMP-9, TIMP-1, and tumor markers correlated with the Duke's stage and were the highest in the sera of CRC patients with stage D. The differences between cancer stages were significant only for TIMP-1 in KruskalWallis test $(p=0.003)$ and were confirmed in post hoc Dwass-Steel-Critchlow-Fligner test for comparison between patients with Duke's stage B and D, as well as between stage $\mathrm{C}$ and $\mathrm{D}$ of CRC patients.

Serum levels of MMP-9, TIMP-1, CEA, and CA 19-9

in CRC patients in relation to clinico-pathological variables of tumor

Table 3 presents concentrations of MMP-9, TIMP-1, CEA, and CA 19-9 in the sera of CRC patients in relation to clinico-pathological variables of tumor. Serum levels of all proteins tested varied according to bowel wall infiltration ( $\mathrm{T}$ factor) and were the highest in the $\mathrm{T} 4$ subgroup, although these differences were not significant.

Serum levels of all biomarkers tested related to nodal involvement, but only the serum TIMP-1 levels revealed significant correlation with $\mathrm{N}$ factor $(p=0.019)$, and were the highest in the N3 subgroup. The statistical significance of these differences were confirmed in post hoc DwassSteel-Critchlow-Fligner test for comparison between N0 and N3 CRC patients.

Similarly, in patients with distant metastases, concentrations of all measurands were increased in comparison with the M0 subgroup. The differences were found to be significant for TIMP-1 $(p=0.001)$ and CEA $(p=0.043)$ in Mann-Whitney test.

Moreover, serum levels of all proteins tested increased in subgroup of CRC patients who died of cancer during the observation period, although the differences were statisti-

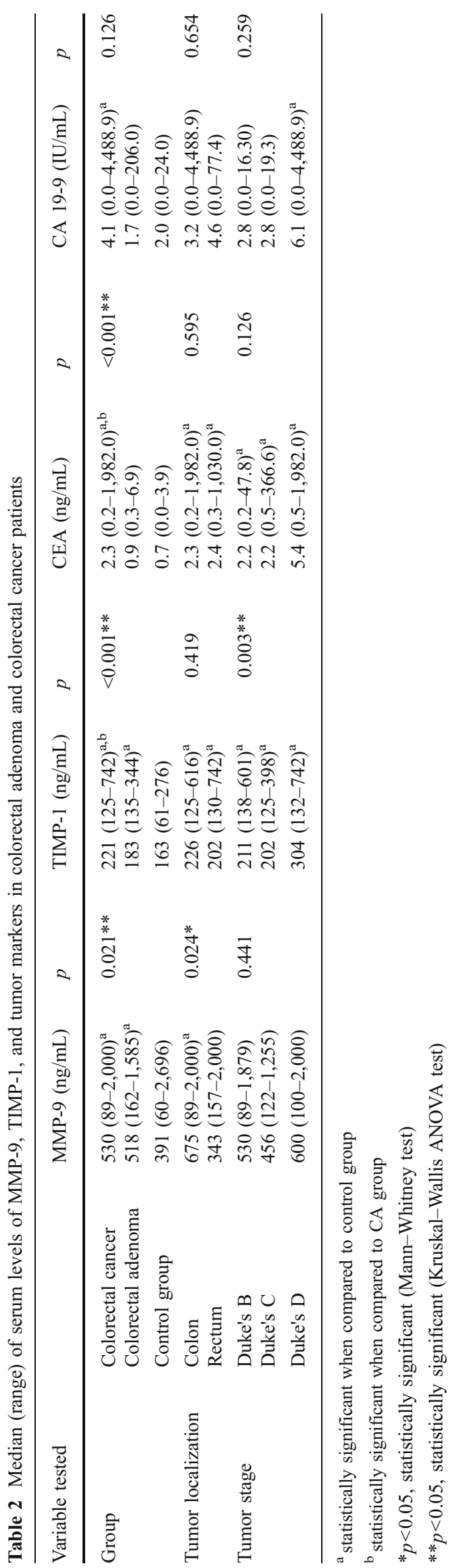


cally significant for TIMP-1 $(p<0.001)$. Similar observations were made in CRC patients with nonresectable tumors compared to those with resectable ones.

The diagnostic criteria for MMP-9, TIMP-1, CEA, and CA 19-9 in CRC patients

The percentage of elevated concentrations of proteins tested in CRC patients (diagnostic sensitivity) is presented in Fig. 1. The diagnostic sensitivity of serum TIMP-1 levels was higher than those of MMP-9, CEA, and CA 19-9. The combined use of MMP-9 or TIMP-1 improved the diagnostic sensitivity of tumor markers. The frequency of increased concentrations was the highest for the combination of MMP-9 with TIMP-1 or MMP-9 with CEA levels (75\%). The TIMP-1 area under ROC curve $(0.8319)$ was higher than the AUC for other markers (Fig. 2). Additionally, we analyzed AUC for differentiation between CRC and CA patients. The highest values were obtained for CEA (0.7735) and TIMP-1 (0.7469) (Fig. 3).

\section{Discussion}

Matrix metalloproteinases are the enzymes involved in tumor progression and may be produced by stromal or tumoral cells [4]. Their natural tissue inhibitors (TIMPs) are induced in stromal cells to regulate the proteinase reactions [27]. Increased expression of MMPs and TIMPs plays a key role in CRC invasion and/or metastasis [28]. It was observed that the levels of MMP-9 and TIMP-1 were elevated in CRC patients in relation to healthy controls [7, 16-18]. Therefore, in order to further evaluate the clinical value of serum MMP-9 and TIMP-1, we determine and compare the diagnostic usefulness of these proteins.

The concentrations of MMP-9 and TIMP-1 in the sera of 75 CRC patients were assessed in relation to clinicopathological features of tumor such as Duke's stage, tumor location, bowel wall infiltration ( $\mathrm{T}$ factor), involvement of regional lymph nodes ( $\mathrm{N}$ factor), presence of distant metastases ( $\mathrm{M}$ factor), tumor resectability, and survival of the patients. Additionally, we compared serum levels of proteins tested in CRC patients with those in $35 \mathrm{CA}$ patients and 70 healthy controls. Moreover, we determined the serum levels of the classical tumor marker for CRC-CEA and CA 19-9.

In the present study, the preoperative serum levels of MMP-9, TIMP-1, CEA, and CA 19-9 were significantly higher in the CRC group than in the healthy subjects, what is in line with results obtained by other authors [7, 16, 17, 21, 29]. Additionally, serum TIMP-1 in CRC patients increased significantly with tumor stage, $\mathrm{N}$ and $\mathrm{M}$ factors, as well as in nonresectable tumors. Our results are in 
Fig. 1 Percentage of elevated levels of MMP-9, TIMP-1, and tumor markers in the sera of colorectal cancer patients

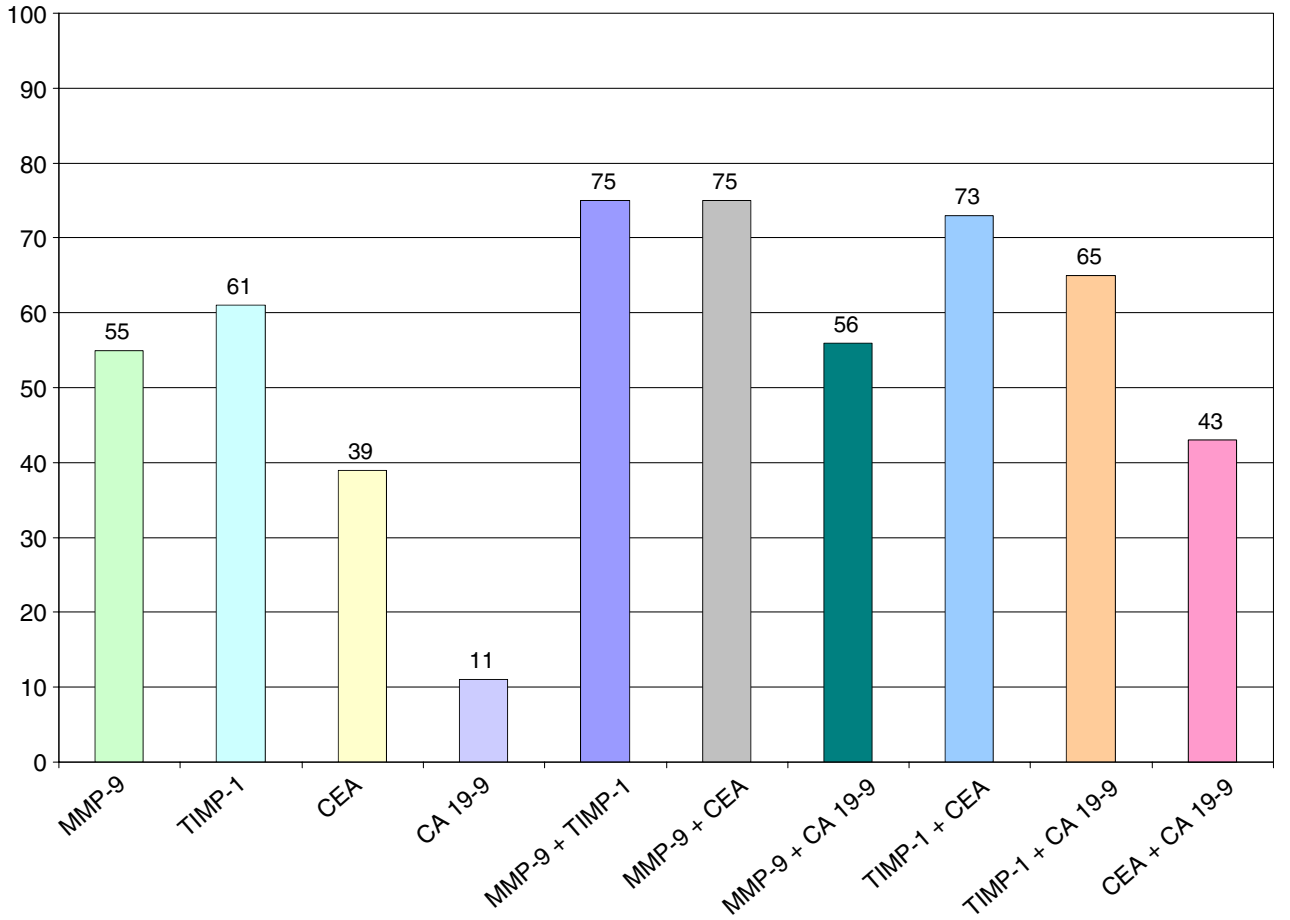

agreement to the findings of Yukawa et al. [19] who revealed significant differences in lymph node metastasis, serosal invasion, curability, and Duke's classification when clinico-pathological factors between patients with positive and those with negative TIMP-1 levels were analyzed. It suggests that the elevated levels of TIMP-1 might reflect the role of this protein as stimulator of tumor growth and malignant transformation [12] or anti-apoptotic factor [13] in colorectal tumor progression.

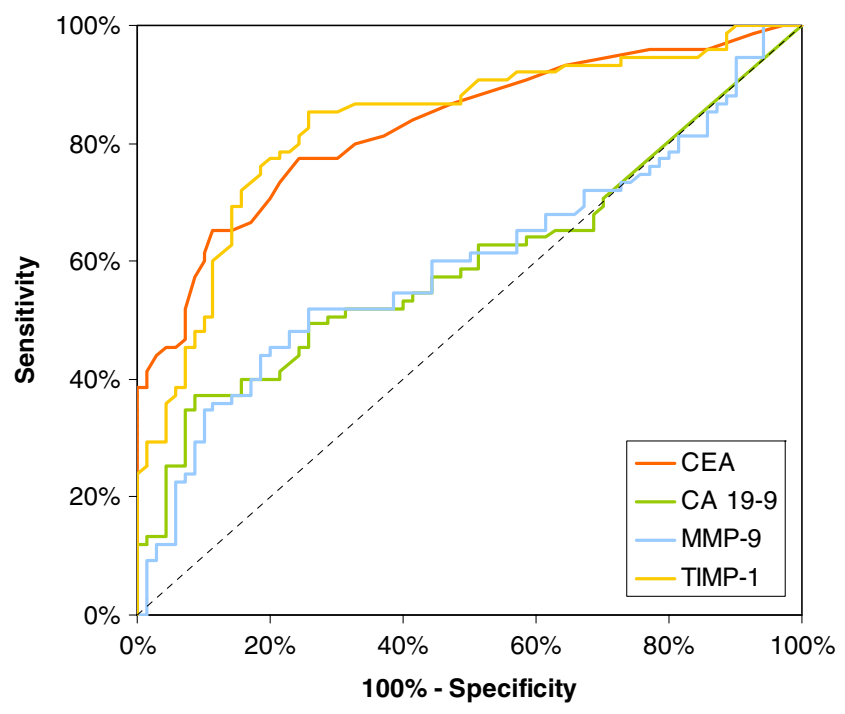

Fig. 2 Areas under ROC curves for TIMP-1 (0.8319), CEA (0.8292), MMP-9 (0.5590), and CA 19-9 (0.5590) in differentiation between colorectal cancer patients and healthy subjects
MMP-9 and TIMP-1 expression in the normal mucosaadenoma-dysplasia-adenocarcinoma sequence of the colon was studied by few authors. Gimeno-Garcia et al. [29] observed enhanced tissue expression of MMP-9 in patients with CA in comparison with normal mucosa. They revealed a significant and progressive increase in the activity of the latent form of MMP-9 at the different types of colorectal neoplasma. Herszényi et al. [22] showed that protein expression of MMP-9 in CRC tissue was significantly

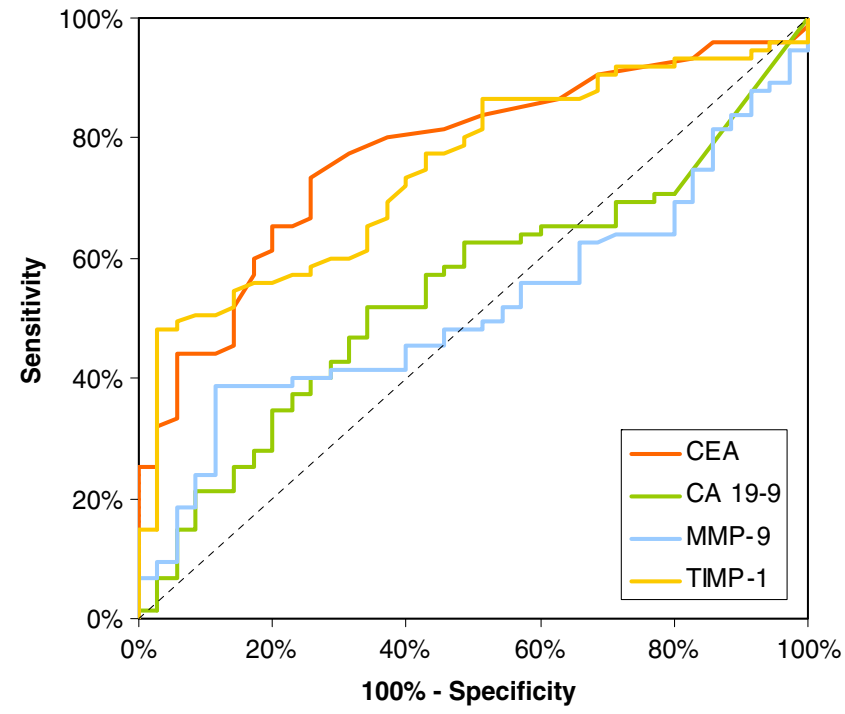

Fig. 3 Areas under ROC curves for CEA (0.7735), TIMP-1 (0.7469), CA 19-9 (0.5463), and MMP-9 (0.5183) in differentiation between colorectal cancer and colorectal adenoma patients 
higher compared to adenomas or the normal mucosa, and staining intensity correlated with the grade of CRC. Additionally, they observed significantly higher expression of MMP-9 in adenomas with high grade dysplasia compared to other adenomas or normal colon. It was demonstrated that the expression of MMP-9 in adenoma with high grade dysplasia- CRC sequence was significantly higher when compared to normal tissue. Tomita et al. showed that TIMP-1 immunoreactivity was detected in both stromal and epithelial cells in colonic polyps and adenomas as well as in adenocarcinomas [23].

In the current paper, the clinical significance of serum MMP-9 and TIMP-1 in the differentiation between CA and cancer was assessed. Holten-Andersen et al. [30] showed no differences between TIMP-1 levels in patients with CA and healthy controls, as well as significantly elevated concentrations of this protein in patients with colonic or rectal cancer in comparison with adenoma and healthy subjects. However, considering the very low number of cancer patients in their study, the relevance of such statistical analysis is limited [30]. In our study, serum levels of TIMP-1 and CEA in adenoma patients were significantly lower than in CRC patients. Moreover, serum concentrations of MMP-9 and TIMP-1 were significantly higher in adenoma patients compared with control group. The statistical differences between serum levels of TIMP-1 in CA group and CRC patients were confirmed in DwassSteel-Critchlow-Fligner post hoc tests, as well as in analysis of area under ROC curve for this biomarker. These results suggest a potential clinical usefulness of pretreatment serum TIMP-1 for the differentiation between malignant and non-malignant tumors; however, our findings require further studies.

In the present paper, we defined the diagnostic sensitivity and AUC for all proteins tested to assess a potential clinical significance of MMP-9 and TIMP-1 as tumor markers in the diagnosis of CRC. We found that the percentage of elevated plasma concentrations (diagnostic sensitivity) of TIMP-1 (61\%) were higher than those of MMP-9 (55\%) and tumor markers (CEA-39\%, CA 19-9-11\%). The diagnostic sensitivity of biomarkers tested increased with their combined use, and were the highest for TIMP-1 with MMP-9 (75\%) and almost twofold higher (43\%) than for combined use of classical tumor markers for CRC-CEA with CA 19-9. Moreover, the analysis of ROC curves indicates the advantage of TIMP-1 measurement over assessment of classical tumor markers CEA and CA 19-9 in CRC patients. We revealed that area under ROC curve for determination of TIMP-1 (0.8319) was higher than for the other biomarkers (CEA, 0.8292; MMP-9, 0.5590; and CA 19-9, 0.5590) in differentiation between CRC patients and healthy subjects. The results of AUC for CEA and CA 19-9 are similar to those obtained in a previous study concerning diagnostic usefulness classical tumor markers in CRC patients [31].

In conclusion, the aim of the present study was to compare the clinical significance of serum MMP-9 with TIMP-1 in the diagnosis of CRC patients and in the differentiation between $\mathrm{CA}$ and cancer. We found that serum levels of these proteins were higher in CRC patient than in healthy subjects. Additionally, serum TIMP-1 was significantly higher in patients with CRC than in CA patients. Concentrations of TIMP-1 correlated with tumor stage, nodal involvement, presence of distant metastases, patients' survival, and tumor resectability. Diagnostic sensitivity of TIMP-1 was the highest among the biomarkers tested. Moreover, the areas under ROC curves of TIMP-1 were larger than those of MMP-9. Our findings suggest better usefulness of TIMP-1 than MMP-9 in the diagnosis of CRC.

Open Access This article is distributed under the terms of the Creative Commons Attribution Noncommercial License which permits any noncommercial use, distribution, and reproduction in any medium, provided the original author(s) and source are credited.

\section{References}

1. Jemal A, Siegel R, Ward E, Hao Y, Xu J, Thun MJ (2009) Cancer statistics, 2009. CA Cancer J Clin (In press)

2. Fearon ER (1995) Molecular genetics of colorectal cancer. Ann NY Acad Sci 768:101-110

3. Fearon ER, Vogelstein B (1990) A genetic model for colorectal tumorigenesis. Cell 61:759-767

4. Vihinen P, Kahari VM (2002) Matrix metalloproteinases in cancer: prognostic markers and therapeutic targets. Int J Cancer 99:157-166

5. Murray D, Morrin M, McDonnel S (2004) Increased invasion and expression of MMP-9 in human colorectal cell lines by a CD44dependent mechanism. Anticancer Res 24:489-494

6. Kim TD, Song KS, Li G et al (2006) Activity and expression of urokinase-type plasminogen activator and matrix metalloproteinases in human colorectal cancer. BMC Cancer 6:211

7. Hurst NG, Stocken DD, Wilson S, Keh C, Wakelam MJ, Ismail T (2007) Elevated serum matrix metalloproteinase 9 (MMP-9) concentration predicts the presence of colorectal neoplasia in symptomatic patients. Br J Cancer 97:971-977

8. Torii A, Kodera Y, Uesaka K et al (1997) Plasma concentration of matrix metalloproteinase 9 in gastric cancer. Br J Surg 84:133-136

9. Ylisirnio S, Hoyhtya M, Turpeenniemi-Hujanen T (2000) Serum matrix metalloproteinases-2, -9 and tissue inhibitors of metalloproteinases-1, -2 in lung cancer-TIMP-1 as prognostic marker. Anticancer Res 20:1311-1316

10. Wu ZS, Wu Q, Yang JH, Wang HQ, Ding XD, Yang F, Xu XC (2008) Prognostic significance of MMP-9 and TIMP-1 serum and tissue expression in breast cancer. Int J Cancer 122:2050-2056

11. Lambert E, Dasse E, Haye B et al (2004) TIMPs as multifacial proteins. Crit Rev Oncol Hematol 49:187-198

12. Hewitt RE, Brown KE, Corcoran M, Stetler-Stevenson WG (2000) Increased expression of tissue inhibitor of metalloprotei- 
nases type 1 (TIMP-1) in a more tumourigenic colon cancer cell line. J Pathol 192:455-459

13. Guedez L, Stetler-Stevenson WG, Wolff L et al (1998) In vitro suppression of programmed cell death of $\mathrm{B}$ cells by tissue inhibitor of metalloproteinases-1. J Clin Invest 102:2002-2010

14. McCarthy K, Maguire T, McGreal G, McDermott E, O'Higgins N, Duffy MJ (1999) High levels of tissue inhibitor of metalloproteinase1 predict poor outcome in patients with breast cancer. Int $\mathrm{J}$ Cancer 84:44-48

15. Lein M, Nowak L, Jung K et al (1999) Metalloproteinases and tissue inhibitors of matrix-metalloproteinases in plasma of patients with prostate cancer and in prostate cancer tissue. Ann NY Acad Sci 878:544-546

16. Oberg A, Hoythya M, Taveli B, Stenling R, Lindmark G (2000) Limited value of preoperative serum analyses of matrix metalloproteinases (MMP-2, MMP-9) and tissue inhibitors of matrix metalloproteinases (TIMP-1, TIMP-2) in colorectal cancer. Anticancer Res 20:1085-1091

17. Ishida H, Murata N, Hayashi Y, Tada M, Hashimoto D (2003) Serum levels of tissue inhibitor of metalloproteinases-1 (TIMP-1) in colorectal cancer patients. Surg Today 33:885-892

18. Holten-Andersen MN, Stephens RW, Nielsen HJ et al (2000) High preoperative plasma tissue inhibitor of metalloproteinase-1 levels are associated with short survival of patients with colorectal cancer. Clin Cancer Res 6:4292-4299

19. Yukawa N, Yoshikawa T, Akaike M et al (2004) Prognostic impact of tissue inhibitor of matrix metalloproteinase-1 in plasma of patients with colorectal cancer. Anticancer Res 24:2101-2105

20. Yukawa N, Yoshikawa T, Akaike M et al (2007) Impact of plasma tissue inhibitor of matrix metalloproteinase-1 on long-term survival in patients with colorectal cancer. Oncology 72:205-208

21. Waas ET, Hendriks T, Lomme RM, Wobbes T (2005) Plasma levels of matrix metalloproteinase-2 and tissue inhibitor of metalloproteinase-1 correlate with disease stage and survival in colorectal cancer patients. Dis Colon Rectum 48:700-710
22. Herszényi L, Sipos F, Galamb O et al (2008) Matrix metalloproteinase9 expression in the normal mucosa-adenoma-dysplasia-adenocarcinoma sequence of the colon. Pathol Oncol Res 14:31-37

23. Tomita T, Iwata K (1996) Matrix metalloproteinases and tissue inhibitors of metalloproteinases in colonic adenomasadenocarcinomas. Dis Colon Rectum 39:1255-1264

24. Liabakk NB, Talbot I, Smith RA, Wilkinson K, Balkwill F (1996) Matrix metalloprotease 2 (MMP-2) and matrix metalloprotease 9 (MMP-9) type IV collagenases in colorectal cancer. Cancer Res $56: 190-196$

25. Jass JR, Sobin LH (1989) WHO international histological classification of tumors. Histological typing of intestinal tumors. Springer-Verlag, New York

26. Mroczko B, Szmitkowski M, Okulczyk B (2003) Hematopoietic growth factors in colorectal cancer patients. Clin Chem Lab Med 41:646-651

27. Sato H, Kida Y, Mai M et al (1992) Expression of genes encoding type IV collagen-degrading metalloproteinases and tissue inhibitors of metalloproteinases in various human tumor cells. Oncogene 7:77-83

28. Ogata Y, Miura K, Ohkita A, Nagase H, Shirouzu K (2001) Imbalance between matrix metalloproteinase 9 and tissue inhibitor of metalloproteinases 1 expression by tumor cells implicated in liver metastasis from colorectal carcinoma. Kurume Med J 48:211-218

29. Gimeno-García AZ, Santana-Rodríguez A, Jiménez A et al (2006) Up-regulation of gelatinases in the colorectal adenoma-carcinoma sequence. Eur J Cancer 42:3246-3252

30. Holten-Andersen MN, Fenger C, Nielsen HJ et al (2004) Plasma TIMP-1 in patients with colorectal adenomas: a prospective study. Eur J Cancer 40:2159-2164

31. Groblewska M, Mroczko B, Wereszczyńska-Siemiątkowska U et al (2008) Serum interleukin 6 (IL-6) and C-reactive protein (CRP) levels in colorectal adenoma and cancer patients. Clin Chem Lab Med 46:1423-1428 